\title{
FEAR AND COURAGE: SOME MILITARY ASPECTS
}

\author{
PROFESSOR S RACHMAN \\ Institute of Psychiatry, University of London
}

Excessive fear is a central component of most neurotic disorders, and therefore, applied psychologists have been obliged to devote a considerable amount of attention to analysing this emotion and to searching for ways of preventing or reducing fear reactions. Fear also presents problems for military commanders who are responsible for preparing and leading their soldiers into dangerous circumstances. It is pleasing to record that considerable progress has been made during the past twenty years; clinical psychologists now have a better understanding of fear and are in a stronger position to help people overcome fears which are disrupting or disabling them.

While making no claim to be a comprehensive account, the purpose of this paper is to draw attention to some of the recent psychological findings that might be of interest and valuable to military personnel.

To begin with, it is necessary to revise the earlier psychological view that fears are easily and rapidly acquired. Research coming from laboratory investigations as well as military observations make it perfectly clear that people acquire considerably fewer fears than most of our psychological theories would lead us to expect. ${ }^{1}$ We have seriously underestimated the degree and extent of human resilience, even under exposure to intense and prolonged stresses of the kind soldiers might be expected to encounter. Prior to the outbreak of the Second World War it was widely predicted that the bombing of civilian populations would result in widespread panic and intense, chronic fear reactions. In fact, there were surprisingly few "fear casualties", even in those areas that were severely bombed." After an initial period of disturbance, most people quickly adapted to the dangers and stresses of repeated bombing attacks. The facilities for dealing with fear casualties were so little required that most of them were closed within the first six months of the heavy bombing raids over England.

Another important aspect of human resilience is that of rapid habituation, or to use a more general term, adaptation. Most civilian populations exposed to repeated attack showed a remarkable degree of adaptation. With some exceptions, ${ }^{3}$ a similar form of adaptation appears to have taken place among military airmen and soldiers. ${ }^{4,5}$

Reviewing the military information on the nature of courage, it is possible to summarise the factors that contribute to courageous performance. ${ }^{1}$ They are: adequate training, good and reliable equipment, high group morale and cohesion, and to some extent the presence of certain personal qualities that will be referred to later. At least as far as Western armies are concerned, explicit ideological factors appeared to play little part in determining combat performance during World War II. However, this may not be true for armies such as those of Red China, ${ }^{6}$ or in the circumstances that arise during a largely ideological conflict such as the Spanish Civil War. ${ }^{7}$ 
In an attempt to extend our understanding of courageous performance and the factors that facilitate it, we selected a military sample consisting of bombdisposal operators who are required to carry out skilled technical acts under conditions of extreme danger. The circumstances under which they are required to carry out their skilled performances seemed to us to provide a particularly good testing ground for some emerging ideas, and at the same time gave us an opportunity to gather information about how technical soldiers can be helped to perform their demanding tasks under conditions of stress.

Initially we conducted a retrospective analysis of over 200 Royal Army Ordnance Corps (RAOC) bomb-disposal operators, both officers and soldiers, who had seen service in Northern Ireland. ${ }^{8}$ The major finding to emerge was that most of this large group of operators performed extraordinarily well; during a roughly ten-year period, they successfully dealt with several thousand explosive devices (IED's). They sustained less than 20 fatalities. Their performance is all the more remarkable for having been carried out by operators who were to a large extent unselected. The major selection procedure used by the RAOC was one of negative exclusion. All of their trained ordnance operators were expected to carry out bomb-disposal duties, after completing an additional course of specialised training - most of them (54\%) were not aware, at the time of joining the Service, that bomb-disposal work might be involved. Before being called upon to carry out such duties each operator was required to complete a set of psychometric tests, undergo a psychiatric interview, pass a series of military interviews and training tasks, and finally complete a course of specialised training. Out of the $200+$ operators who underwent these tests and training in the period 19721980, the surprisingly low figure of less than $10 \%$ were rejected. Of these, fewer than $5 \%$ were rejected on psychiatric grounds. The bold implicit expectation underlying the selection criteria operated by the RAOC is that virtually all of their soldiers, officers and non-commissioned officers, are capable of carrying out this difficult and dangerous work providing they are given specialised training, in addition to their normal training courses. This apparently optimistic expectation, likely to provoke derision among applied psychologists, has however been borne out by events in the remarkable manner mentioned above.

The psychometric information shows that the operators were, with very few exceptions, people of stable personality and a high level of competence. On most of the psychometric tests they were above the normal civilian population norms on all those characteristics that we would regard as indicating psychological health. ${ }^{8}$

We then carried out a comparison between those operators who at the end of their tour of duty received ratings above average, average or below average, from their commanding officers. There were surprisingly few differences between the operators in these three categories. There was however a slight tendency for the above average operators to be a little more calm, confident and psychologically fit than the other operators -- bearing in mind that the total sample consisted of people who were unusually competent and well. Continuing our search for markers that might indicate whether there exists a select few who are capable of carrying out acts of exceptional courage that distinguish them from their fellow 
(highly competent) operators, we carried out separate analyses of decorated operators and ordinarily competent operators. ${ }^{9}$ To our surprise we came across one feature that distinguished the decorated operators. They were found to be slightly but significantly superior in all round psychological health and bodily fitness. They said that they felt well in their bodies and mentally fit and alert even to a greater degree than their highly competent colleagues who scored well above civilian norms. The opposite charactertistic to that reported by the decorated soldiers is described as "hypochondriasis", and on this scale most of the decorated operators returned zero scores! In other words they had no bodily or mental complaints - whatsoever.

Although most of the evidence which we gathered points to the overwhelming importance of training, group cohesion and situational determinants, this finding on the decorated group of operators suggests that individual characteristics do make some contribution to the execution of acts of bravery. In other words, there are courageous actors as well as courageous acts.

We next turned our attention to the effects of training and were able to find clear evidence of a substantial increase in skill and confidence after completion of the specialised training course. The value of the course is emphasized by the finding that after completing it, the novice (i.e. those who had not yet carried out a tour of duty as a bomb-disposal operator) expressed approximately $80 \%$ of the confidence of the experienced operators. To put it another way, the training course succeeded in taking them $80 \%$ of the way towards that desirable combination of confidence and competence that make a successful operator. The specific value of the training is evident from our finding that prior to entering the course, soldiers with previous military experience in Northern Ireland unrelated to bomb-disposal duties, had as little confidence (regarding IED tasks) as those soldiers who had never served in Northern Ireland.

Our next investigation dealt with the adjustment of the operators during a tour of duty in Northern Ireland. The most important fact is that almost all of them performed their duties successfully and without problems. Moreover they quickly adapted to the dangers of their work, despite the fact that most of them had to live and work under constricted and rather difficult, improvised conditions. The process of adaptation was accelerated once the operator successfully carried out his first operation on a genuine device. Experience of dealing with hoaxes or false alarms made no additional contribution to their confidence or competence. However, once the inexperienced operators successfuly completed one IED task, their confidence and feelings of competence rose close to the level of the experienced operators. During the entire tour of duty most of the operators reported feeling calm and relaxed. There were very few occasions on which any serious degree of apprehension or dysphoria was elicited. The exceptions were one operator who had a serious breakdown shortly after returning from a tour of duty, and other operators who had short periods of psychological disruption following the death of, or serious injury to, a member of their small unit. We did find however that experienced operators were better able to adjust their level of arousal to on-duty and off-duty periods; they could "switch on" and "switch off" more discriminatively. 
We also have some information about how the bomb-disposal operators adjust to their life and duties after completing a tour in Northern Ireland. For experienced operators, the post-tour adjustment was almost always uneventful. In the case of inexperienced operators the post-tour adjustment sometimes was bumpy. Many of them reported a feeling of being let down when they returned to the usually undemanding and more leisurely existence of home base service. We also came across an interesting finding that among those operators who had experienced a difficult or demanding tour there were signs of significant psychological change in the post-tour period. Both the operators themselves and their spouses (answering separately) reported more changes in this group of operators. In a number of cases the marriages were discernably altered, sometimes in the form of greater closeness, and in others, leading to separation. As far as the soldiers themselves were concerned, many reported that they felt significantly more mature and confident as a result of having completed a difficult tour of duty.

As is plain from what has already been said, the (negative) selection process, and the training procedures, are unusually successful. Insofar as these findings have applications for the training of other soldiers who have to carry out difficult tasks under conditions of stress, the following suggestions might be worth considering. As far as possible the tasks should be structured so that the operator can acquire considerable skill and confidence in his own ability and in the reliability and quality of the equipment. These are important contributors to successful performance. The planned and constructive use of group support makes a useful contribution to competent and calm performance. The tasks should be structured in such a way as to give the soldier a sense that he has a reasonable degree of control over events, and attempts should be made to arrange S.O.P. so that the operator is kept as active as possible as long as possible. Prolonged periods of inactivity are likely to impair his performance. In summary, the conditions that are best avoided include the following: unreliable or unfamiliar equipment, a sense of uncontrollability of equipment or requirements of the task, prolonged periods of inactivity, exposure to stress while isolated, inadequate training, training that is too remote from actual conditions in the field.

As far as the concept of courage is concerned, the main determinants of courageous behaviour include perceived competence, excellence of training and high group morale and cohesion. In addition to these determinants of courageous acts, we have gathered some slight evidence of the existence of a small group of exceptional people - unusually competent, confident and calm people who provide the courageous actors.

\section{Acknowledgements}

The research work referred to in this paper was supported by a grant from the European Research Office, to whom I am indebted. I also wish to thank the officers and men of the Royal Army Ordnance Corps for their excellent cooperation, and the several psychiatrists and psychologists of the RAMC who provided assistance. 


\section{REFERENCES}

1. Rachman $S$. Fear and Courage. Freemans: 1978.

2. LEWIS A. Incidence of neurosis in England under war conditions. Lancet 1942; 2: 175-183.

3. Grinker R and Spiegel S. Men under stress. Churchills: 1945.

4. JANIS I. Air War and Emotional Stress. McGraw-Hill: 1951.

5. STOUfFer et al. The American Soldier: Combat and Its Aftermath. Princeton University Press: 1949.

6. Grorge A. The Chinese Communist Army in Action. Columbia University Press: 1967.

7. Dollard J. Fear in Battle. The Infantry Journal. Washington DC: 1944.

8. Rachman S. Technical Reports, European Research Organization. Details of the research methods, findings and analyses referred to in this paper are contained in this Series (1979-1981).

9. Hallam $\mathbf{R}$ and Rachman S. Courageous acts or courageous actors? Pers Indiv Diffs $1980 ; 1: 341-346$. 